\title{
The Micro-Analysis of Regional Economy in China
}

A Perspective of Firm Relocation 


\section{Series on Chinese Economics Research}

(ISSN: 2251-1644)

Series Editors: Yang Mu (National University of Singapore, Singapore) Fan Gang (Peking University, China)

\section{Published:}

Vol. 1: China's State-Owned Enterprises: Nature, Performance and Reform by Sheng Hong and Zhao Nong

Vol. 2: Food Security and Farm Land Protection in China by Mao Yushi, Zhao Nong and Yang Xiaojing

Vol. 3: The Micro-Analysis of Regional Economy in China: A Perspective of Firm Relocation by Wei Houkai, Wang Yeqiang and Bai Mei 
Series on Chinese Economics Research - Vol. 3

\title{
The Micro-Analysis \\ of Regional Economy \\ in China
}

A Perspective of Firm Relocation

\author{
Wei Houkai \\ Wang Yeqiang \\ Bai Mei
}

Chinese Academy of Social Sciences, China

Unirule Institute of Economics 


\title{
Published by
}

World Scientific Publishing Co. Pte. Ltd.

5 Toh Tuck Link, Singapore 596224

USA office: 27 Warren Street, Suite 401-402, Hackensack, NJ 07601

UK office: 57 Shelton Street, Covent Garden, London WC2H 9HE

\author{
Library of Congress Cataloging-in-Publication Data \\ Wei, Houkai. \\ The micro-analysis of regional economy in China : a perspective of firm relocation / \\ Wei Houkai, Chinese Academy of Social Sciences, Wang Yeqiang, Chinese Academy of Social \\ Sciences, Bai Mei, Chinese Academy of Social Sciences. \\ pages cm. -- (Series on Chinese economics research; v.3) \\ ISBN 978-9814452250 -- ISBN 9814452254 \\ 1. Industrial location--China. 2. Industries--China. 3. Regional planning--China. \\ 4. Regional economics--China. I. Wang, Yeqiang, 1972- II. Mei, Bai. III. Title. \\ HC430.D5W447 2013 \\ $338.50951--d c 23$
}

2013007837

\section{British Library Cataloguing-in-Publication Data}

A catalogue record for this book is available from the British Library.

《中国区域经济的微观透析：企业迁移的视角》

Originally published in Chinese by Economy \& Management Publishing House of Beijing

经济管理出版社, 北京

Copyright@经济管理出版社，北京 2010

Copyright (C) 2014 by World Scientific Publishing Co. Pte. Ltd.

All rights reserved. This book, or parts thereof, may not be reproduced in any form or by any means, electronic or mechanical, including photocopying, recording or any information storage and retrieval system now known or to be invented, without written permission from the Publisher.

For photocopying of material in this volume, please pay a copying fee through the Copyright Clearance Center, Inc., 222 Rosewood Drive, Danvers, MA 01923, USA. In this case permission to photocopy is not required from the publisher.

In-house Editor: Lum Pui Yee

Typeset by Stallion Press

Email: enquiries@stallionpress.com

Printed in Singapore 


\section{Contents}

Preface $\quad x i$

List of Tables $\quad$ xxi

List of Figures $\quad$ XXV

List of Abbreviations $\quad$ xxvii

Chapter 1. Regional Economic Development in China: Agglomeration and Relocation 1

Wei Houkai

1.1 Division of Economic Regions and Characteristics of Regional Economic Development in China . . . . . . . . . . . 2

1.2 Disequilibrium in Regional Economic Development:

A Growing Tendency . . . . . . . . . . . . . . . . . . 6

1.3 Metamorphosis of China's Regional Economic Disparity . . . 12

1.4 Concentration of Economic Activities and Its Influences . . . 16

1.5 From Concentration to Diffusion: A New Trend in Industrial Relocation in China . . . . . . . . . . . . . . 19

1.6 Conclusions ...................... 25

References . . . . . . . . . . . . . . . 26

Chapter 2. Theoretical Issues in the Current Regional Economic Development

Wei Houkai

2.1 The Selection of Central Regional Policy Goals . . . . . . . . 29

2.2 The Gradient Theory and the Gradient-Transfer Strategy . . . 35

2.3 The Migration of Labor and Movement of Jobs . . . . . . . 40

2.4 Spatial Agglomeration of Economic Activities . . . . . . . . 45

References . . . . . . . . . . . . . . . . . 49 


\section{Chapter 3. A Critical Review of Theoretical Research on Firm Relocation}

Bai Mei

3.1 Factors Influencing Firm Relocation . . . . . . . . . . . . 54

3.2 Dynamic Mechanism of Firm Relocation . . . . . . . . . . 57

3.3 Research on Firm Relocation in China . . . . . . . . . . . . . 64

3.4 Conclusion . . . . . . . . . . . . . . . 66

References ........................ 68

\section{Chapter 4. Characteristics and Tendency of Enterprise} Relocation in China

Wei Houkai and Bai Mei

4.1 The Concept and Classification of Enterprise Relocation . . . 71

4.2 Course of Enterprise Relocation in China . . . . . . . . . . 75

4.3 Characteristics of Enterprise Relocation in China . . . . . . . 81

4.4 Determinants of Enterprise Relocation in China . . . . . . . . 88

4.5 The Future for Chinese Enterprise Relocation . . . . . . . . . 95

4.6 Policy Suggestions on Promoting Enterprise Relocation . . . 103 References . . . . . . . . . . . . . . . . . 106

\section{Chapter 5. Dynamics and Determinants} of Manufacturing Location in China

Wang Yeqiang and Wei Houkai

5.1 Literature Review . . . . . . . . . . . . . . . . . . . . . . 110

5.2 Agglomeration and Diffusion: A Comprehensive Theoretical Framework . . . . . . . . . . . . . . . . . 112

5.3 Statistical Description of Manufacturing Location Change in China . . . . . . . . . . . . . . . . 118

5.4 Model and Variables Selection . . . . . . . . . . . . . . . 120

5.5 Empirical Results Analysis . . . . . . . . . . . . . . . . . . 127

5.6 Conclusions . . . . . . . . . . . . . . . . 141

References . . . . . . . . . . . . . . . . . 143 


\section{Chapter 6. Manufacturing Location Change in China:} Structural Effects and Spatial Effects: A Test of the "Krugman Hypothesis"

Wang Yeqiang and Wei Houkai

6.1 Literature Review: The Development of "Krugman Hypothesis" . . . . . . . . . . . . . . . . . . . 147

6.2 Analyzing Methods and Models . . . . . . . . . . . . . 151

6.3 Statistical Analysis of Manufacturing Location Changes in China . . . . . . . . . . . . . . . . . 157

6.4 Further Decomposition of the Competition Effect . . . . . . . 165

6.5 Conclusion . . . . . . . . . . . . . . . . 175

References .................... 176

\section{Chapter 7. Manufacturing Firm Relocation in East}

China: Tendency and Mechanism

Jiang Yuanyuan

7.1 Theoretical Explanation of Firm Relocation . . . . . . . . . . 182

7.2 Research Methods and Data Source . . . . . . . . . . . . . . 184

7.3 Industrial Characteristics and Tendency of Firm Relocation of Eastern Manufacturing Industry . . . . . . . . . . . . . 185

7.4 Mechanism of Manufacturing Industry's Westward Relocation from East China . . . . . . . . . . . . . . . . 192

7.5 National Policy for Guiding the Eastern Manufacturing Industry to Move West . . . . . . . . . . . . . . . . 206 References . . . . . . . . . . . . . . . . . . . 208

Chapter 8. Changes in the Location of Taiwan-Invested IT Enterprises in Mainland China and Their Relocation Decisions

Wei Houkai and Li Jing

8.1 General Situation of Taiwanese Investment in Mainland China . . . . . . . . . . . . . . . . . 211

8.2 Data Source and Research Direction . . . . . . . . . . . . . 214 
8.3 Distribution Characteristics and Location Changes of Taiwan-Invested IT Enterprises . . . . . . . . . . . . 216

8.4 Location Choice and Relocation Determinants of Taiwan-Invested IT Enterprises . . . . . . . . . . . . . . 233

8.5 Suggestions on the Localization of Taiwan-Invested IT Enterprises . . . . . . . . . . . . . . . . . . 241

References . . . . . . . . . . . . . . . . . 244

\section{Chapter 9. Corporate Headquarters Relocation of Listed} Companies and Wealth Transfer in China

Wei Houkai and Bai Mei

9.1 Introduction . . . . . . . . . . . . . . . 247

9.2 Advances in Domestic and Foreign Research . . . . . . . . . 249

9.3 Characteristics of HQs Relocation among China's Listed Companies . . . . . . . . . . . . . . . . . 251

9.4 Reasons and Target Locations for Chinese Listed Companies' HQs Relocation . . . . . . . . . . . . . . . . . . 264

9.5 Concluding Remarks . . . . . . . . . . . . . . . . . . . . 279

References . . . . . . . . . . . . . . . . . 280

\section{Chapter 10. Relocation Mechanism and Spatial} Agglomeration of Enterprise R\&D Activities

Liu Changquan

10.1 Characteristics and Types of Enterprise R\&D Relocation in China . . . . . . . . . . . . . . . . . . . . . . 284

10.2 Micro Analysis of R\&D Relocation: Mechanism and Influencing Factors . . . . . . . . . . . 287

10.3 R\&D Relocation in China at Macro Level:

State and Trends . . . . . . . . . . . . . . . . . . . 290

10.4 Conclusion . . . . . . . . . . . . . . . . 305

References . . . . . . . . . . . . . . . 306 


\section{Chapter 11. New Industrial Division and Conflict} Management in Metropolitan Area — Based on the Perspective of Industrial Chain Division

Wei Houkai

11.1 Conflicts Growing in Intensity in Metropolitan Area . . . . . 309

11.2 To Adopt a Correct Attitude Toward Industrial Conflicts in Metropolitan Area . . . . . . . . . . . . . . . . . . . 312

11.3 New Industrial Division and Pattern of Metropolitan Labor Division . . . . . . . . . . . . . . . . . . 317

11.4 Conflict Management Based on Industrial Chain Division in Metropolitan Area . . . . . . . . . . . . . . . . 322

References . . . . . . . . . . . . . . . 325

\section{Chapter 12. Analysis of Urban Industrial Relocation's} Incentive, Approaches and Effects — Taking Beijing as an Example

Fu Xiaoxia, Wei Houkai and Wu Lixue

12.1 General Theories of Urban Industrial Relocation . . . . . . . 328

12.2 General Situations of Industrial Relocation in Beijing . . . . . 332

12.3 Typical Cases of Urban Industrial Relocation in Beijing . . . 334

12.4 Comparative Analysis of Industrial Relocation in Beijing . . . 337

12.5 Conclusion Remarks . . . . . . . . . . . . . . . . . . . 342

References . . . . . . . . . . . . . . . . 343

Index 
This page intentionally left blank 


\section{Preface}

Since the reform and opening-up, the Chinese economy has grown at a rapid and continuous pace. From 1979 to 2011, China's Gross Domestic Product (GDP) grew by $9.9 \%$ annually. Even when faced with the impact of the global financial crisis and the European debt crisis, the growth rate of China's GDP between 2009 and 2011 was as high as 9.6\%. If we calculate according to the speed of growth of each province, autonomous region, and municipality, the average growth rate of Gross Regional Product (GRP) of each region has reached $12.2 \%$ among the three years. With the rapid growth of economy, the living standard of the people has significantly improved. The comprehensive national power and competitiveness have been strengthened incessantly. The national economic aggregate rose from the tenth place globally to the second place in 2010. Impoverished population numbers were substantially reduced, decreasing from 0.25 billion at the early stage of the reform and opening-up to 26.88 million $^{1}$ in 2010 . The academia at home and abroad term the stunning accomplishment and rapid growth of Chinese economy since the reform and opening-up alternatively as "Chinese miracle", "Chinese model", and "Chinese experience".

Obviously, the fast growth of the Chinese economy is supported by regional economic prosperity. We can safely state that, without the common prosperity of each region's economy, the unrelenting rapid growth of the national economy cannot be sustained. Since the reform and opening-up, although the regional economic growth rate differs from region to region, large-scale growth on the whole has been achieved, and every regional economy has the tendency to grow rapidly. Based on our measurement, from 1980 to 2009, the annual average growth rate of the 31 provinces, autonomous regions, and municipalities has reached $11.1 \%$, among which the eastern region's growth rate stands at $12.1 \%$, the northeastern region

\footnotetext{
${ }^{1}$ Measured according to the 1274 Yuan poverty standard in 2010.
} 
$9.6 \%$, the central region $10.5 \%$, and the western region $10.2 \%$. This illustrates that since the reform and opening-up, no matter whether eastern region, the central and western region, or the northeastern region, the economic growth rate is fairly rapid, presenting the feature of typical high growth. The rapid growth rate of more than $9 \%$ for the past 30 years in each region is unprecedented, which is very rare from an international perspective.

It is predictable that, in the coming decade or two, the Chinese regional economy will maintain this fast growth. First, influenced by the lack of industrial land and increase of factor price and environmental protection standards, although the eastern region slacks off its economic growth, with the acceleration of the economic transition and upgrade, it will soon enter a new round of sustainable fast growth. Second, the central and western region's resources are rich, the cost of the factor price is low, the supply of labor is adequate, and the space and potential for future development is ample; thus, in recent years, this region shows a strong growth. The GRP growth rate of central and western regions, respectively, reached up to $12.7 \%$ and $13.7 \%$ from 2008 to 2011 , which were much high than that of the eastern region $(11.2 \%)$ and the entire country $(12.1 \%)$. Third, with the powerful support of the national policy, the Northeast Industrial Base was pulled out of "relative degradation" since the reform and opening-up. The annual average GRP growth rate reached $13.4 \%$ during 2006-2011 and 13.1\% during 2008-2011. It's quite hopeful to realize the goal of overall revitalization. Fourth, in the past, the rapid economic growth of the Chinese was supported mainly by the few regions like Yangtze River Delta (YRD) region and the Pearl River Delta (PRD) region. In recent years, with the promotion of the urbanization and industrialization, a climax of boosting urban agglomeration development has swept the whole nation. The Beijing-Tianjin-Hebei metropolitan area, Shandong peninsula urban agglomeration, Liaoning coastal economic belt, Zhongyuan urban agglomeration, Wanjiang urban belt, Changsha-Zhuzhou-Xiangtan " $3+5$ " urban agglomeration, Chengdu-Chongqing economic region, GuanzhongTianshui economic region, Beibu Gulf economic region, etc., have the potential to become the pillars of rapid growth of Chinese economy as the new dominant regions, thereby forming a diversified competitive pattern of "rise of various regions". 
However, we should understand that the fast growth of regional economy since the reform and opening-up has been realized at the expense of high consumption, high emission, in coordination, and unplanned exploitation, of which high consumption comes at the top. In 2010, China's GDP accounted for $9.5 \%$ of the world's total, yet the consumption of cements took up $56.2 \%$ of the global quantity, ${ }^{2}$ the primary energy consumption took up $20.3 \%$, among which the coal occupied $48.2 \%,{ }^{3}$ the apparent consumption of the steel took up 44.9\%. ${ }^{4}$ According to the WDI database of the World Bank, in 2007, China's energy consumption per ten thousand USD of GDP reached 7.96 ton oil equivalent, which is 2.71 times the average level of the world, and 4.28 times of the high-income countries. ${ }^{5}$ Especially in the central and western region and northeastern region, influenced by the industrial structure and the technologic and management level, the feature of high consumption of resources and energy is more manifest. In 2009, energy consumption per 10,000 Yuan of GDP in the western region takes up 1.57 ton coal equivalent, which is $41.4 \%$ higher than the national average and $80.5 \%$ higher than the eastern region. Even in the developed eastern region, the per unit GDP's consumption strength of resources and energy is a far cry from the developed countries.

What comes second is the high emission. According to the data issued by the International Energy Agency (IEA), the emission of carbon dioxide of China in 2009 has taken up $23.6 \%$ of the world's total. Although the per capita carbon dioxide emission of China equals that of the world average and it is equivalent to $52.2 \%$ of the OECD countries, its emission strength per unit GDP is 3.19 times that of the world average and 5.68 times that of the OECD countries. ${ }^{6}$ Per unit GDP's emission strength of sulfur dioxide is far higher than the level of the developed countries. In 2006, China's sulfur dioxide emission per 10,000 Yuan of GDP is 0.012015 tons, which

\footnotetext{
${ }^{2}$ International Cement Review (ICR) (2011). Global Cement Report, (10).

${ }^{3}$ BP Company (2011). BP World Energy Statistics 2011, June.

${ }^{4}$ World Steel Association (WSA) (2011). World Steel Short Range Outlook, WSA.

${ }^{5}$ National Bureau of Statistics of China (NBSC) (2011). International Statistical Yearbook, China: China Statistics Press.

${ }^{6}$ International Energy Agency, Key World Energy Statistics 2011, OECD/IEA, 2011.
} 
is 59.6 times that of the US and 19.8 times that of Japan. ${ }^{7}$ If judged from region to region, although $50 \%$ of the total quantity of industrial waste air and waste water is concentrated in the eastern region, the "three wastes" emission per unit industrial value-added in the central and western region is far higher than that of the eastern region, presenting a typical high emission feature. In 2007, the waste water, waste air, and waste solid's emission per 100 million Yuan industrial value-added in the western region is 1.79 times, 2.46 times, and 48 times that of the eastern region, respectively. Thus, we can conclude that the task of emission reduction of the central and western region is arduous.

The third is the in coordination, mainly shown in the following aspects: (1) Pursuing the GDP growth blindly and ignoring the structural upgrade, technologic innovation, social development, and construction of ecological environment, which gives rise to the in coordination of the economic and social development and the construction of ecological environment; (2) The in coordination of regional development: Since the reform and opening-up, the developmental difference between the eastern region and the central and western region is widening and has been improved in recent years; (3) The in coordination of urban and rural development: Since the mid 1980s, apart from few years, the income difference between urban and rural residents is always widening. In 2011, the ratio of the per capita disposable income of the urban households to per capita net income of rural households reaches 3.13:1, much higher than the 2.48:1 in 1997 and 1.86:1 in 1985 ; (4) The in coordination between the population and industry distribution: In recent years, while industries have concentrated in some cities and metropolitan areas, the population does not concentrate accordingly, which has given rise to a serious mismatching between the job vacancies and population distribution. Although 150 million rural migrant workers have worked in urban region, ${ }^{8}$ they have not received a fair share of the accomplishments of urbanization. For example, in 2010, the population of

\footnotetext{
${ }^{7}$ Tie, Z. (2010). China's Ecological Civilization Construction Enters Quantization Age, Scientific Times, 5, February.

${ }^{8}$ In 2011, according to the calculation of the sampling investigation data of the NBSC, the amount of national migrant workers is 252.78 million, among which the out-migrant workers are 158.63 million. These out-migrant workers mainly work in urban regions.
} 
China's three metropolitan areas (the YRD, the PRD, and Beijing-TianjinHebei regions) took up $16.57 \%$ of the total, but the GRP took up $33.78 \%$, the ratio between which was 1:2.04. However, the northeast mega-region' population took up $17 \%$ of the US, the GDP $20 \%$, the ratio between which was only $1: 1.18$. In developed countries like Japan, the national population distribution basically matches the allocation of economic activities.

Fourth is unplanned exploitation as revealed in the following aspects: (1) Blind exploitation of the countryside causes the sharp decrease of the arable land and the supply of the agricultural products faced with threat; (2) Reckless exploitation of the ecological area has aggravates the integral function of the ecological system, with the result that more and more land is becoming non-inhabitable space; (3) the over-exploitation of the urban areas makes the pressure of resources and environment bigger and bigger. The result of unplanned exploitation is the disorder of territorial development and inappropriateness of spatial structure. From the perspective of production and its impact on ecology and life, the former takes up more space, leaving little to the ecology and life. From the angle of countryside and urban area, the habitancy space of countryside becomes more and that of the urban areas becomes less. Judging from the interior of the city, the industrial space is more and the habitable space becomes less. ${ }^{9}$ Especially in recent years, some areas produce "garden factories" and conduct "land enclosure" and the rapid economic growth is mainly dependant on the usage of land expansion. Therefore, from the angle of land exploitation, we can state that, in the past, the industrialization of not a few regions was at the expense of the inhabitant welfare. The industrial land's scale is too big, the proportion is high and the use efficiency is too low.

(III)

Recalling the process of the regional development since the reform and opening-up, we can clearly see that, in the past, each regional development was on the traditional development path of high growth rate, high consumption, high emission, unplanned exploitation, and in coordination. Under the restriction of the resources and environment, this traditional

\footnotetext{
${ }^{9}$ Yang W. (2008). Promote the Establishment of Main Functional Area, Optimize the Pattern of Spatial Exploitation. Economic Review, (5).
} 
development model is at its wits end. It is neither sustainable nor in compliance with the spirit of the scientific outlook on development. In particular, the international financial crisis since the second half of 2008 has accelerated the collapse of the traditional development model. Under new circumstances, the regions cannot and should not pursue development depending on the large consumption, high emission of "three wastes", and great exportation of cheap products. They must establish a new scientific outlook on development and continue to developing scientifically and unswervingly. It is safe to state that the regional development with a scientific view will become the core concept of China's regional development in the future. Future regional development will enter into a new epoch, highlighting development with scientific view.

Aiming at the past traditional development model, early in October 2003, the Third Plenary Session of the 16th Central Committee of Communist Party of China (CPC) proposed scientific outlook on overall development that is human-oriented, harmonious, and sustainable. Overall development, harmonious development, and sustainable development are the three core concepts of scientific outlook on development. Therefore, the path of regional development with scientific view insists upon the overall, harmonious, and sustainable development based on human-oriented. It underscores the intensive development, innovation development, harmonious development, and improvement of the regional sustainable development ability. From the perspective of scientific outlook on development, we must accelerate the transformation of regional development pattern and the transition of development model, changing from the traditional development model into the new development model with scientific view as soon as possible. This regional development transition includes the diversified and comprehensive transition of economic, social, cultural, and thinking concepts, the development strategy, and policies. On the whole, the regional development transition in present-day China includes six aspects: First, the transition of growth pattern from the extensive to intensive; Second, the transition of development focus from the economic growth to the improvement of quality, the social development and the improvement of livelihood; Third, the transition of industrial structure from the lower end of industrial chain to the middle and higher end; Fourth, the transition of urban and rural relations from dual division to integration; Fifth, the transition 
of motivation source from the input-driven to innovation-driven (including the technological innovation, institutional innovation, management innovation and brand innovation); Sixthly, the transition of spatial structure from unplanned exploitation to orderly exploitation.

Hence, we must implement five new strategies, accelerating the overall transition of regional development strategy. First is the implementation of new industrialization strategy. Judging from the large area, the regions suitable for industrialization can be identified from the local situation, highlight its features and advantages, and embark on the resource-saving, environmentally-friendly, high productivity, creativity-oriented industrialization path which gives full play to human resources and shares the development accomplishment. ${ }^{10}$ Second is the implementation of the new urbanization strategy. The key is to establish a new urban ecological outlook, to highlight the urban features, to underscore the improvement of urban efficiency, and to persist with balancing urban and rural development. It must emphasize the improvement of the urban spatial structure and embark on the new, human-based, intensive, open, harmonious, diversified, and sustainable urbanization path. Third is the implementation of new exploitation strategy. On one hand, we should divide the control line of spatial exploitation scientifically, implement strict spatial governance and plan the spatial exploitation order reasonably; on the other, we should promote the synergistic agglomeration of population and industries, the coordination between population distribution and economic activity allocation, as well as the adaptability of population, economy and carrying capacity of resources and environment. Fourth is the implementation of a new opening strategy. The key is to balance opening-up to the outside world and domestic development is to start with the promotion of reform, development, upgrade, coordination, and harmony by opening-up, comprehensively improving the open economy level and promoting the economic and social development and the construction of a harmonious society. Fifth is the strengthening of the new social management. We should highlight the community management, give full play to the important role of intermediary organizations and public

\footnotetext{
${ }^{10}$ In China, the industrialization strategy is not suited for every region. At the same time, the industrialization strategy aims at the bigger areas, for the smaller areas, especially the geographic units below counties shall emphasize the thinking of functional division and specialization.
} 
participation, and explore the new social management system which adapts to the scientific outlook on development.

Since the reform and opening-up, China's regional development has achieved quite a few accomplishments, but there are several problems pertaining to development. In the course of development, we shall not underplay the considerable achievement of reform and opening-up because of these problems. It is just because of the new problems and new phenomena which crop up in the pursuance of regional development, do various regions explore and innovate in the reform and opening-up practice, creating positively new models, experience, and ways; in reality, these have provided colorful and rich materials for the research of China's and even world's regional development theories. It has also offered favorable conditions for the China's regional economics to stand at the summit of the world.

Chinese academia has always highlighted the research of China's regional development. In recent years, this kind of research is conducted in three directions, the first is the comprehensive research at the national level, which mainly explores the basic features, evolution tendency, and existing problems, dynamic mechanisms, strategy models, policy choice, and so on; the second is the specific study of each field, which covers almost every field concerning the whole regional economic, social, scientific, education, and cultural development and the construction of ecological environment, and so on. The third is research at the local level, the four levels of regional development: provincial development, municipal development; and countylevel development; and township, village, and industrial zone development, which have become the hot subjects of the academic research. The research of development strategy planning on various-level region is always on the bloom.

The Chinese Academy of Social Sciences (CASS) has the tradition of highlighting the problems faced in reality. The construction of the regional economics discipline has underscored the positive exploration on the reality problems in China's regional development. From 2003 to 2008, I was honored to chair the construction project of regional economics discipline of "Key Discipline Construction Projects" at the CASS. Since 2008, based on 
the key discipline construction, the specialists and scholars of the CASS as the main body, with the enormous support of the Economy and Management Publishing House, jointly compiled China's Modern Regional Development Series. The first batch has 12 books. The smooth publication of the series is the result of the enormous support of the Chief Editor Zhiyu Shen, the President Shixian Zhang of the Economy and Management Publishing House, and friends and scholars from domestic and overseas academia. To them I present my sincere thanks!

This book is part of China's Modern Regional Development Series and the final outcome of the National Natural Science Foundation project "The Determinants of Firm Relocation and Location Policy in China" chaired by me, and it is also the collective wisdom of the group members.

The creation and publication of the book in the Chinese version has obtained strong support from the Institute of Industrial Economics, the Economy and Management Publishing House, and other institutes and departments at the CASS, and also of the academic colleagues in China. As for the English version of this book, I should firstly give my great thanks to Professor Dr. Mu Yang of East Asian Institute (EAI) at the National University of Singapore (NUS) for including this book into the Chinese Economy Series. I am also extremely thankful to the World Scientific Publishing Co. Pte. Ltd, especially to the editor Ms Lum Pui Yee. Besides, the smooth publication of the English version of this book has received the support of the Philosophy and Social Science Innovation Programme at the CASS. The Postdoctoral candidates Hongjian Su and Zhanyun $\mathrm{Wu}$, and doctoral candidates Yan Zhang, Yebo Guo, Lianlei Bai, and Ning Wang are partly responsible for the proofreading and typesetting of the English text. I am grateful for their support!

Wei Houkai

5 March 2009, Revised 22 October 2012 Zhonghai Andrews Manor, Beijing 
This page intentionally left blank 


\section{List of Tables}

Table 1-1 Division of Chinese Economic Regions Since the Reform and Opening-up . . . . . . . . . . . 3

Table 1-2 Percentages of Major Economic Indicators for China's Four Regions in National Total in $2010(\%)$. . . . . . . 6

Table 1-3 The Changing GRP Growth Rates in the Eastern, Northeastern, Central, and Western Regions _. . . . 9

Table 1-4 Growth Rates and Regional Distribution of Investment in Fixed Assets in China . . . . . . . . . . . . . . . 21

Table 1-5 FDI Actually Utilized in Different Regions of China . . 23 Table 2-1 Average Tax Bearing of Industrial Enterprises Above Designated Size in Various Parts of China . . . . . . . . 31

Table 4-1 Summary of Metropolises' Enterprise Relocation . . . . 78

Table 4-2 Factors Affecting Enterprise Relocation in China . . . . 89

Table 4-3 2007-2008 Comprehensive Land Price . . . . . . . . . 92

Table 4-4 Recent Region Planning and Related Policies Approved by the State Council . . . . . . . . . . . . . . . 96

Table 5-1 Trend of Manufacturing Output Share in Different Regions (\%) . . . . . . . . . . . . . . 121

Table 5-2 The Interaction Table of Variables in The Model . . . . 123

Table 5-3 Market Factors Regression Results (a) . . . . . . . . . 128

Table 5-4 Market Factors Regression Results (b) . . . . . . . . . 132

Table 5-5 Financial Factors Regression Results . . . . . . . . . . 134

Table 5-6 High-Tech Industry Regression Results . . . . . . . . . 137

Table 6-1 Decomposition of Manufacturing Output Growth Effects of China's Four Regions . . . . . . . . . . . 159

Table 6-2 Decomposition of Growth Effects of Top Five Growth of Manufacturing Industries in China's Four Regions 2000-2005 . . . . . . . . . . . . 161

Table 6-3 Decomposition of Growth Effects of Chinese Manufacturing Output 1985-2005 . . . . . . . . . . 166 
Table 6-4 Further Decomposition of the Spatial Dependence Model . . . . . . . . . . . . . . . 171

Table 6-5 Further Decomposition of Spatial Filtering Model . . 173

Table 7-1 Enterprise Theory and Industrial Location Theory . . . 183

Table 7-2 Determining Factors of Relocation . . . . . . . . . . . 184

Table 7-3 Market Share Change of Manufacturing Industry in Different Regions (\%) . . . . . . . . . . . . . 186

Table 7-4 The Characteristics and Tendency of Westward Relocated Manufacturing Industry from the Eastern Developed Region . . . . . . . . . . . . . . . . 190

Table 7-5 Manufacturing Industry Location Quotient of Three Regions in 2007 . . . . . . . . . . . . . . . 196

Table 7-6 Comparison of Efficiency Wage of Manufacturing Industry between Eastern Developed Region and Central and Western Regions . . . . . . . . . . . . . . . . 199

Table 7-7 Comparison of Average Price for Industrial Land in Each Region $\left(\right.$ Yuan $\left./ \mathrm{m}^{2}\right)$. . . . . . . . . . . . . . 201

Table 7-8 Comparison of Average Profit Rate of Manufacturing Industry between the Eastern Developed Region and Central and Western Regions . . . . . . . . . . . . 203

Table 7-9 Comparison of Per Capita Productivity of Manufacturing Industry between the Developed Eastern Region and Central and Western Regions . . . . . . . 204

Table 8-1 Economic Styles of Taiwan-Funded IT Enterprises in the Mainland (Registered in and Before 1997) . . . . . . 218

Table 8-2 Distribution of Taiwan-Funded IT Enterprises in the Mainland (Registered in and Before 1997) . . . . . . . 219

Table 8-3 State of Taiwan-Invested IT Enterprises in the Major Provinces (Registered in and Before 1997) . . . . . . . 220

Table 8-4 State of Taiwan-Invested IT Enterprises in the Major Cities (Registered in and Before 1997) . . . . . . . . . 221

Table 8-5 Economic Styles of Taiwan-invested IT Enterprises in the Mainland (1998.1-2001.12) . . . . . . . . . . . . 223

Table 8-6 Distribution of Taiwan-invested IT Enterprises in the Eastern Region (1998.1-2001.12) . . . . . . . . . . 224 
Table 8-7 State of Taiwan-Invested IT Enterprises in the Major Provinces (1998.1-2001.12) . . . . . . . . . . 225

Table 8-8 State of Taiwan-invested IT Enterprises in the Top 10 Cities (1998.1-2001.12) . . . . . . . . . . . . . 227

Table 8-9 Distribution of Taiwan-Invested IT Enterprises in the Mainland (2002.1-2006.2) . . . . . . . . . . . . . 230

Table 8-10 State of Taiwan-invested IT Enterprises in the Major Provinces (2002.1-2006.2) _ . . . . . . . . . 231

Table 8-11 State of Taiwan-invested IT Enterprises in the Major Cities (2002.1-2006.2)

Table 8-12 Determinants of Location and Relocation of Taiwan-Invested IT Enterprises . . . . . . . . . . . . 234

Table 8-13 The Average Cost of Essential Factors in Some Areas of the YRD and PRD . . . . . . . . . . . . . . 238

Table 8-14 Effect of Local Promoting Factors on the Investment and Relocation of Taiwan-Invested IT Enterprises . . . 242

Table 9-1 A Comparison of Corporate HQs Relocation Rate . . . 252 Table 9-2 Listed Companies' HQs Relocations by Region . . . . . 255 Table 9-3 Listed Companies' HQs Relocations by Province . . . . 256 Table 9-4 Listed Companies' HQs Relocations in Major Cities . . 259 Table 9-5 The Distance of Listed Companies' HQs Relocation in China . . . . . . . . . . . . . . . . 260

Table 9-6 The Quantity and Distance of Different Types of Relocation . . . . . . . . . . . . . . . . . . . 263

Table 9-7 Listed Companies' HQs Relocation Types . . . . . . . 265

Table 9-8 Listed Companies' HQs Relocation Types by Region . . 266 Table 9-9 Listed Companies' HQs Relocation Types by City . . . 267 Table 9-10 Listed Companies' HQs Relocation Matrix in China . . 268 Table 9-11 Cost of Labor in 2007 by Region . . . . . . . . . . . . 270 Table 9-12 Comparison between "West to East" and "East to West" Relocation . . . . . . . . . . . . . . 271

Table 9-13 The HQs Relocations of Tibet's Listed Companies . . . 272 Table 9-14 Concentration of China's Top 100 Listed Companies Between 2005 and $2006 \ldots \ldots$. . . . . . . . 274

Table 9-15 Gains of Wealth Caused by Listed Companies' HQs Relocation into Provinces (RMB 100 Millions) . . . . . 275 
Table 9-16 Losses of Wealth Caused by Listed Companies' HQs Relocations Out of Provinces (RMB 100 Millions) . . . 276

Table 10-1 Changes in the Regional Distribution of Funds Raised for S\&T Activities from 1997 to 2008 . . . . . . . . . 293

Table 10-2 Changes of Regional Distribution of R\&D Investment from 1998 to $2010 \ldots \ldots$. . . . . . . . . 295

Table 10-3 Cumulative Proportion of R\&D Resources in the Areas with the Highest or Lowest Proportions from 1998 to 2010 . . . . . . . . . . . . . . 298

Table 10-4 Distribution and Changes of R\&D Investment in Large and Medium-Sized Enterprises from 1998 to 2010 . . . 299

Table 10-5 Distribution of R\&D Activities from 1998

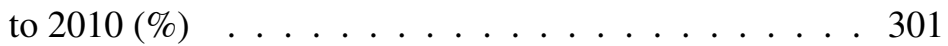

Table 10-6 Estimation Results . . . . . . . . . . . . . . . . . . . 304

Table 11-1 Sectoral Specialization and Functional Specialization of US Cities . . . . . . . . . . . . . . . 315

Table 11-2 The Specialization of Clothing Production in Zhejiang Province . . . . . . . . . . . . . . . . 316

Table 11-3 Basic Patterns and Features of Regional Industrial Division . . . . . . . . . . . . . 319

Table 12-1 Urban Industrial Relocation vs. Voluntary Enterprise Migration . . . . . . . . . . . . . 330

Table 12-2 Comparison on Industrial Relocation in Different Phases ...................... 338 


\section{List of Figures}

Figure 1-1 Three Times Main Changes in the Economic Division of China in Recent Years . . . . . . . . . . . . 5

Figure 1-2 Comparisons between GDP and GRP Growth Rates in China during the 1980-2010 Period . . . . . . . 7

Figure 1-3 Changes in GRP Growth-rate Differentials for the Four Regions of China . . . . . . . . . . . 10

Figure 1-4 Changes in the GRP Growth Rates in 31 Provinces, Municipalities and Autonomous Regions . . . . . . . . 11

Figure 1-5 Relative Levels of the Per Capita GRP for the Four Regions of China . . . . . . . . . . . . . . 12

Figure 1-6 Changes in Per Capita GRP Relative Disparity in the Four Regions of China . . . . . . . . . . . . . 13

Figure 1-7 Changes in Per Capital GRP Disparities among Provinces in China . . . . . . . . . . . . 15

Figure 1-8 Growth Rate of Population in Various Regions of China between 2005 and $2006 \ldots \ldots$. . . . . . . . 16

Figure 1-9 Changes in the Share of GRP in Various Regions . . . 17

Figure 1-10 The Shares of Three Coastal Regions in China's Total Value of FDI Actually Utilized . . . . . . . . . . . . 22

Figure 5-1 Trend of China's Manufacturing Spatial Change . . . . 119

Figure 6-1 Trend of Structural Effect and the Competition of the Top 3 Industrial Output Value Growth 1985-2005 . . . 165

Figure 7-1 Market Share Change of Labor-Intensive Manufacturing Industry in Different Regions . . . . . 188

Figure 7-2 Market Share Change of Raw-Material-Intensive Manufacturing Industry in Different Regions . . . . . 188

Figure 7-3 Market Share Change of Capital and TechnologyIntensive Manufacturing Industry in Different Regions . . . . . . . . . . . . . . 189 
Figure 8-1 Changes of the Actual Utilization of Taiwanese Direct Investment in the Mainland China . . . . . . . . . 212

Figure 8-2 Distribution of Taiwanese Investment in Mainland China from 1996 to 2008 . . . . . . . . . . . . . 213

Figure 10-1 Location Choice and Relocation Decision of R\&D Activities . . . . . . . . . . . . . . . 288

Figure 10-2 Changes in the Proportion of Fund Raised for S\&T Activities in Four Regions from 1997 to 2008 . . . . . 292

Figure 10-3 CV of Investment in S\&T Activities at Province Level from 1997 to 2005 . . . . . . . . . . . . . . . 294

Figure 10-4 CVs of R\&D Inputs in China from 1998 to 2010 . . . 296

Figure 10-5 Regional Distribution of Investment in R\&D activities and Its Change . . . . . . . . . . . . . 297

Figure 10-6 GRP per capita and per capita Internal Expenditure of R\&D Personnel (Full-time Equivalent) in Different Regions in 2010 . . . . . . . . . . . . . . . 304

Figure 11-1 Change of China's Urban Population and Urbanization Rate . . . . . . . . . . . . . . . . . 310

Figure 11-2 Labor Division System of Industrial Chain in the Metropolitan Areas . . . . . . . . . . . . . . 321

Figure 12-1 The Optimal Structure of Urban Land Utilization . . . 331 


\section{List of Abbreviations}

BSR Bohai Sea Rim

CASS Chinese Academy of Social Sciences

CPC Communist Party of China

CV Coefficient of Variation

FDI Foreign Direct Investment

GDP Gross Domestic Product

GRP Gross Regional Product

HQs Headquarters

ICR International Cement Review

IEA International Energy Agency

NBSC National Bureau of Statistics of China

NDRC National Development and Reform Commission

ODM Original Design Manufacturer

OEM Original Equipment Manufacturer

PRC People's Republic of China

PRD Pearl River Delta

R\&D Research and Development

S\&T Science and Technology

SIC Standard Industrial Classification

SMEs Small and Medium Enterprises

UNIDO United Nations Industrial Development Organization

WSA World Steel Association

YRD Yangtze River Delta

ZSP Zhongguancun Science Park 